\title{
Towards Successful Outsourcing of Human Resource Functions
}

\author{
Fapohunda, Tinuke. M \\ Department of Industrial Relations and Public Administration \\ Lagos State University Ojo. Nigeria \\ Email: tkfap@yahoo.com
}

\author{
Accepted: August 07, 2013 Published: Sep 04, 2013 \\ Doi:10.5296/ijhrs.v3i3.4227 URL: http://dx.doi.org/10.5296/ijhrs.v3i3.4227
}

\begin{abstract}
Organizations respond to challenges and demands for greater performance with various programmes designed to overcome obstacles and enhance business performance. One of such responses is outsourcing and it can be highly controversial. This article outlines some of the attractions and challenges of outsourcing human resource functions to give a realistic view of what can be achieved through outsourcing. The effects of outsourcing are contingent on factors like focus on core competencies; make or buy decision, clarity about outsourcing needs, gaining full support and cooperation from employees, training courses and seminar sessions. Facilitators of the effective outsourcing include explicit goals and expectations, identifying clear objectives and expectations of outsourcing, good choice of outsourcing partners, rebuilding trust among workers, acquiring the right people with the right skills in outsourcing, adequate supporting infrastructures, commitment by top management, development of objective performance criteria, adequate performance feedback, emphasis on both short and long-term benefits, anticipation of change and flexibility. Despite its limitations and difficulties, outsourcing increases profit levels, market share and customer satisfaction but must be carefully handled, so as to not allow diminishing returns to set in.
\end{abstract}

Keywords: Outsourcing, Human, Resources, Functions, Successful

\section{Introduction}

In today's business world consumers are more demanding than before. The lifestyle expectations of the whole population have increased steadily and they continue to rise. With higher expectations and more choice, the individual consumer is less tolerant of poor products and services and is more vocal in expressing dissatisfaction. The industrial consumer is less willing to condone failure. There is also increased pressure to deliver shareholder value. The need to gain competitive edge in this highly competitive environment, has given rise to various strategies and management techniques for effectiveness and efficiency such as management by objective, total quality management, change management, stress management, downsizing and outsourcing. Organizations are 
being transformed from highly integrated ones producing and delivering goods and services themselves to much more specialized enterprises that contract out to the market place for many goods and services. The increased competitive aspects and the importance of increasing bottom line performance have caused management to seek ever increasing cost-saving solutions such as outsourcing which is seen as being contributory to organisational efficiency and effectiveness and is aimed at minimizing costs and maximizing profits. Outsourcing as an alternative for today's businesses has become a standard feature in modern organization. Dwyner and Tanner (1999) describes outsourcing as the process of finding other organizations to supply the buying organization with products or services, usually those that was previously created in-house. It is a strategic trend, caused in part by a trend in strategy where organizations focus on their core businesses. Although most outsourcing issues are centred on transferring management and handling of technology to highly specialized organizations, it often involves other departments like human resources. Considerations with regards to human resource management issues add complexity to the entire outsourcing landscape.

Sinderman (1995) and Carney (1997) suggest that outsourcing providers are taking increasing responsibility in realms that have traditionally remained in-house. Camey (1997) notes that 42 percent of communication firms, 40 percent of computer manufacturers and 37 percent of semiconductor companies in the US rely on global outsourcing. A survey conducted by the National Manpower Board in 2009, indicates that more than 73 percent of Nigerian business organizations surveyed were involved in at least one type of outsourcing function. Jennings (1996) affirms that human resource expenses are the primary reasons behind outsourcing.

Initially, much of outsourcing was concerned with easily definable issues previously carried out internally. Such activities remain a part of the outsourcing continuum today, but the big opportunities in outsourcing is in strategic partnership with organisations for specific but not always easy-to-define, state of activities. It is not uncommon now for a whole department to be fully outsourced. While outsourcing may prove highly beneficial for many organizations, it also has many drawbacks. It is important that each organization accurately assesses their needs to determine if outsourcing is a viable option. Often, moves to integrate outsourcing within the overall strategic management of an organization can be highly controversial. While some studies on outsourcing tend to favour its use because of the perceived and actual benefits others are not so sure yet of its long term effects. It is important to consider both sides of the outsourcing business because while it may be a boom to those that host outsourced services, it can also be a bane to affected business and ind ustries.

Outsourcing has matured into an indispensable management tool. Drucker (2003) notes that of all the powerful management tools to emerge in the last half of the 20th century outsourcing uniquely compels managers to ask "what to do," thereby increasing the central management challenge. All of the elements of outsourcing combined are what make it a unique management practice. Outsourcing providers are partners, given significant managerial discretion for how to deliver the service, who manage the day-to-day delivery of that service. The value they create is based on being long-term partners who understand the business, can deliver on the requirements of the relationships, and look ahead to how they can better service client firms. 
2. The Objectives

Synergy is acquired through outsourcing and successful outsourcing has become a key to competitiveness. This paper explores key issues associated with the implementation of human resource outsourcing and examines its prospects and challenges to present a realistic idea of what can be achieved through human resource outsourcing. It discusses the merits, demerits, challenges and how to implement successful outsourcing for organisational goals achievement.

\section{Lite rature}

\subsection{The Concept of Outsourcing}

Outsourcing according to Sampson (2007) is the transfer of internal business functions, plus any associated assets, to an external supplier or service provider who offers a defined service for a specified period of time, at an agreed but previously defined price. Outsourcing is often used as an umbrella term for a variety of different arrangements, not all of which involve adding value or the permanent transfer of human resources. It involves moving some of an organization's internal activities and decision responsibilities to external service providers. Outsourcing employs competent individuals or organisations to perform certain functions that are not of the organisation's core competence. In essence, it means contracting some functions or jobs to the competent hand of either an individual or organisation. Outsourcing has been introduced as a vehicle for effecting changes that would be hard to implement internally.

While temporary, contingency and executive search firms have provided staffing services for many decades, the concept of outsourcing the management and ownership of part or all of an organization's human resource process wasn't first realized on a consistent basis until the 1970s. More and more organizations are outsourcing

various aspects of their businesses, especially non-core operations such as administrative functions (secretaries, receptionists etc), customer service desks and call centres.

Outsourced staffing allows the management of the company to dedicate their energies to running the profit centres, which results in effective service delivery. Human resource functions such as pensions, payroll and recruitment have typically been outsourced. But more specialist aspects such as training and performance appraisals have been subject to outsourcing too.

Basically, outsourcing human resources functions can offer many advantages some of which include improved communications, faster feedback, rapid problem solving, computerized training, do it yourself, human resource development programmes among others. These elements can help improve employee morale and service levels with effective professionalism.

The delivery channels for outsourcing human resource functions involve e-human resource and human resource service centres. The drivers for outsourcing human resources are frequently quoted as reducing costs and improving service delivery. Outsourcing appears to encourage the measurement of the value of human resources, and Gregg (2004), suggests that this comes about through the need for service level agreements and key performance indicators with a greater focus on customer satisfaction. A further advantage that is claimed is 
that the internal human resource functions can now concentrate on driving the direction of human resources rather than carrying out more mundane tasks.

From a global perspective, there are various opportunities for tapping into human resource skills from different countries around the world. Countries are provided with the needed employment and investment opportunities.

Obviously, there are possible job repercussions of outsourcing. There are job losses and outsourcing trends have been blamed for these events. Management outsources mainly to cut costs; reduce management and operational problems to more manageable levels and to take advantage of cheap but quality human resource skills available elsewhere. All of these factors greatly contribute to uneasiness and loss of job security. As businesses continue to re evaluate their, efficiencies, and core competencies, outsourcing continues to influence their overall corporate strategies. Human Resources departments are outsourcing a large portion of their functions and activities to third-party firms capable of performing their jobs. Elmuti (2003) reports that more than two thirds of large U.S. corporations have outsourced five or more of their human resource functions.

Globalisation came with the deregulation of not only the product markets but also the labour market. It promoted outsourcing. With globalisation, outsourcing provides an easier way to cut costs and run off competition. This practice has become a gold rush for many organisations in recent times. Today, if an employer was to outsource either human resource or production components, such employer no longer needed as much permanent employees as before. Rather, the popular practice is to cut the number of permanent employees and replace them with casuals. The abundance or excess supply of human resource also played a major role in fuelling outsourcing.

\subsection{Principles of Outsourcing}

Goffredson et al (2005) developed the sourcing opportunities map to determine which functions have the highest outsourcing potentials and which should remain under an organization's control. The less proprietary and the more common a function is, the stronger a candidate it is for outsourcing. Outsourcing is built around basic principles like corporate focus on core competencies; make or buy decision, clarity of outsourcing needs, choosing the right outsourcing provider, attention to details of service agreement, knowledge transfer, evaluation systems, effective communication strategy, gaining employee support and cooperation.

Focus on Core Competencies: Hamel (2004) affirms that a core competence is a bundle of skills and technologies that enables a company to provide a particular benefit to customers. Today's organisations focus on what they are good at which means a careful assessment of core competences and strategically outsourcing many other activities. It is strategically restructuring the organisations around core competencies. Outsourcing also allows organizations to focus on other business issues while having the details taken care of by outside experts. This means that a large amount of resources and attention, which might fall on the shoulders of management professionals, can be used for more important, broader issues within the company. The outsourcing partner is often streamlined, and has capabilities 
and access to new technology that an organization couldn't afford to buy on its own. Again, in cases of expansion, outsourcing is a cost-effective way to start

building foundations in other locations.

The Make or Buy Policy: The make or buy policy is mainly about cost reduction and profitability. The decision to make or buy some component parts or services is important. The most powerful argument for partnership is that it enables synergy of different competencies of different organizations to be formed thereby providing maximum returns from investment, than when an organization does it alone. It reduces labour costs, frees up capital, and improves workers productivity.

Clarity on Outsourcing Needs: A specific principle of outsourcing is clarity about outsourcing needs. With clear reasons an organization is able to achieve the full benefits of outsourcing functions.

Choosing the right Outsourcing Provider: To gain the full benefit from outsourcing, organizations must ensure that outsourcing providers meet the requirements in terms of qualifications, skills, and knowledge. This could be done by requesting for a trial period or a demonstration, or a track record and detailed references from outsourcing providers.

Attention to Details of Service Agreement: Close attention must be paid to the details of the service agreement. Where clear and specific contracts are not created the resultant effects could include lack of attention to the outsourcing process, inability to meet business requirements and timeframes, and low service standards. Unclear agreements or contracts increase the risks involved in an outsourcing relationship and lead to conflict and a lack of cooperation between the provider and internal employees. Consequently, nothing should be assumed and everything should be written in the service agreement with the contract clearly defining the scope of work, cost, duration, performance measures, penalties, and evaluation proposals.

Knowledge Transfer: Attention must be paid to knowledge transfer. It is important that knowledge or techniques used by the outsourcing provider be transferred to the internal employees; otherwise organizations would lose internal skills and knowledge.

Evaluation Systems: Paying close attention to evaluation systems is very important in any successful outsourcing efforts. Organizations should establish and keep an eye on evaluation systems as a follow up activity after implementing the outsourcing service. There is need to evaluate how the outsourcing function can be modelled to fit the ove rall business strategy and objectives so that focus is maintained and employees take necessary ownership. The evaluation should involve checking on the outsourcing progress in all targeted categories, such as skill acquisition, timing, problems encountered, and means elected to resolve any conflicts. Evaluating and reviewing with 360-degree feedback ensures a more holistic view and systematic evaluation of the success of the outsourcing service.

Effective Communication Strategy: There is a need to create an effective communication strategy for outsourcing to be successful. In order to gain full support and cooperation from employees, the organization should consider the effects of outsourcing on the employees and communicate these issues to them. Two-way communication is key in the relationship between managers and employees, or employees and the outsourcing provider. Elmuti 
(2003) asserts that organizations could decrease a negative effect, like low levels of morale and employee performance, by creating effective communication across organizations. With an effective communication strategy the organization maintains a high level of process performance; avoids a negative feeling from employees (e.g. job insecurity); protects organizational reputation by avoiding propaganda or gossip issues; helps organization to build a good relationship between internal employees and outsourcing provider, and maintains high levels of morale and energy of employees.

Creating effective communication strategy involves dealing with the communication strategy. The details of the outsourcing must be communicated across the organization using a range of management tactics. Training courses and seminar sessions could create a good relationship leading to a positive work outcome. Also, organizational announcements, regular meetings, and seminars with employees are a best practice solution to ensure a high degree of communication and reduce any signs of negativity towards the outsourcing. Regular and precise communication could create a high level of trust between all parties.

\subsection{Methods of Outsourcing}

In practice, there are two major approaches to outsourcing each with different objectives and involving different levels of value. First is the Traditional Method which focuses on cost reduction, imposing control and aligning with fundamentally uncharged business processes. It focuses on avoiding doing internally what others could do more efficiently and effectively externally. It is about leveraging economies of scale, skill and technology access to cut costs and deliver enhanced properly managed service levels.

Second, is the Transformational method which targets and enables paradigm shifts. While the traditional method involves doing the same thing better, cheaper and better, the transformational method helps to create a new business model and a new management approach. It draws the attention of management from the non core areas of the business to the core areas of the business.

\subsection{Merits of Outsourcing}

The drivers for the outsourcing decision especially in terms of human resource outsourcing are frequently quoted as reducing costs and improving service delivery. Organizations outsource various jobs for different reasons, but the most prominent advantage as previously mentioned seems to be the fact that it often saves money. Organizations that provide outsourcing services are able to do the work for considerably less money, as they don't have to provide benefits to their workers and have fewer overhead expenses to worry about.

Outsourcing appears to encourage the measurement of the value of human resources, and Gregg (2004), suggests that this comes about through the needs for service level agreements and key performance indicators with a greater focus on customer satisfaction. Aswathappa (2006) asserts that it allows a firm to focus on activities that represent its core competencies thereby creating competitive advantage while reducing cost. Bowersox (1994); Elmuti (2003) and Lojeski (2004) indicate that the decision to outsource is often made with a view to reducing cost, improving quality, improving delivery and reliability, gaining access to resources, establishing presence in foreign markets, focusing on core competencies and 
reducing the size of specialized skills and knowled ge needed for operations.

Elmuti (2003) identifies ten reasons for outsourcing which are to: red ucing cost, improving quality, improving delivery and reliability, using resources not available internally, accessing new technology, accessing materials only available abroad, establishing presence in a foreign market, maintaining sufficient flexibility to respond to market conditions, reducing the overall amount of specialised skills and knowled ge needed, making capital funds available for more profitable operations and focusing on core competencies.

Wikipedia (2009) notes that organizations that outsource seek to realize benefits or address issues like: cost savings, focus on core business, cost restructuring, improved quality, knowledge, contract, operational expertise, access to operational best practices that would be too difficult or time consuming to develop in-house, access to a larger talent pool, capacity management, serving as catalyst for change, enhancing capacity for innovation, reducing time to market, commoditisation, risk management, venture capital, and tax benefit.

Goffredson, Puryear, \& Philips (2005) identifies reasons for outsourcing and entering a strategic alliance to include: improved access to capital and new business; greater technical critical mass, sharing risk and liability; better relationships with strategic partners; techno logy transfer benefits; reduced research and development costs; use of distribution skills; access to marketing strengths; access to technology; standardization; by-product utilization and management skills.

The foregoing implies that cost reduction and cost structure optimization is one of the major driving forces of outsourcing. In low income countries labour is cheap compared to wages in developed countries. Again labour, overhead costs are also often much lower in low income countries. Further, by outsourcing, organizations can lower and also re-engineer and optimise their cost structures. Outsourcing can also help to achieve more predictable cost levels.

Next is immediate access to technology. Technology changes rapidly and following all the developments is very time and resource consuming. Outsourcing can shorten the learning curve of new technologies and reduce cost spent on training. Added to this is immediate access to technical staff. One of the advantages of off-shore outsourcing is the immediate availability of the required number of qualified technical staff.

As opposed to where sometimes there are challenges of finding the right people at the right time or keeping them with an organization, low income (or developing) countries often have qualified, well educated technical staff in abundance. There is also focus on core competences. By outsourcing non-core activities, an organization can free up resources to sharpen its focus on core competences.

Immediate access to business domain expertise is another driving force for outsourcing. Another is flexibility and scalability. Sometimes flexibility and scalability becomes more important than saving cost and outsourcing provides flexibility and scalability both in terms of people and technology. There is also the hour work cycle advantage.

\subsection{Demerits of Outsourcing}

Outsourcing is not without demerits. Typically, the demerits bother mainly on lack of trust, risk and uncertainty the market, longevity and poor performance and the use of hard power as well as issues of complaint about internal alliances. In addition outsourcing often eliminates 
direct communication between an organization and

its clients preventing it from building solid relationships with its customers often leading to dissatisfaction on one or both sides.

Next is the danger of not being able to control some aspects of the organization, as outsourcing may lead to delayed communications and project implementation. Again, sensitive information becomes more vulnerable, and an organization may become very dependent on its outsource providers, leading to problems should the outsource provider back out on their contract suddenly.

In Nigeria, the outsourcing human resources has often led to disparity in the conditions of work, causing a great deal of unhealthy relationship amongst staff. Disparities in wages and conditions of employment, has opened up division on the 'shop floor' between workers in different categories and affects the ways workers view themselves in the workplace. Outsourced workers often feel detached from their jobs. Internal workers may also feel that outsourced workers are threatening their jobs. Consequently there could be job dissatisfaction which has been identified as the bane of poor employee commitment and lower productivity.

\section{Towards Successful Outsourcing}

Outsourcing must be done carefully, systematically, and with explicit goals and expectations. Elmuti (2003) affirms that organizations that have been successful in outsourcing identify clear objectives and expectations of outsourcing activities as the most useful and contributing factors to their outsourcing efforts. A good choice of outsourcing partners is also a useful and contributing factor for successful outsourcing.

Murray (200I) asserts that outsourcing partners should be selected based not only on their expertise in the operation being outsourced and but also their cultural fit with the outsourcing organization. Furthermore a poor choice of sourcing partners may be alleviated by establishing strategic supplier alliances and adoption of the philosophy that the firm is partner with the supplier.

A third factor is the provision of adequate training skills needed to manage outsourcing activities and to negotiate a sound contract. Sinderman (1995) notes that pro viding managers with skills that will enable them to adapt to other cultures and work with other managers is important to ensuring the success of outsourcing. The individuals responsible for managing the outsourcing relationship should receive specific training that includes a complete understanding of the business goals of the contract, the specific performance criteria agreed to, and individual roles. Foster (1999) notes that training and communication can also help reduce resentment or resistance.

Outsourcing efforts are often faced with resistance to change and fear of job loss. Dealing with these fears through communication and honesty is important to managing this factor. In addition, the development of a comprehensive plan outlining detailed expectations, requirements, and expected benefits during all phases of outsourcing activities is key to successful sourcing efforts.

Next is effective communication among cross-functional areas which reduces the negative effects of outsourcing on the morale and performance of employees. The trust among workers must be rebuilt, with jobs re-evaluated and expanded or changed to fit the new organisation. 
Trust is critical to the success of any outsourcing effort. The trust must be institutionalised so that when the founder of the trust departs, it can continue. Trust is the basis for the alignment of the interest of multiple parties in state of individual differences in values and goals. The basis for trust is the elimination or near complete elimination of major surprises. When trust is institutionalized and based on smart contract, a clear process governing how to work together harmoniously and keep the relationship healthy is established. Jones (1999) and Foster (1999) suggest that to achieve this there is need for top management support and involvement in providing incentives to employees and vendors who meet and exceed the contracted performance expectations. Lack of high-level management support can constitute a serious problem.

The effects of outsourcing on the morale and performance of employees could become a most serious obstacle

to the success of outsourcing. Therefore, keeping people informed every step of the way and working out a deal perceived as fair for them is important because an organization trades not only its physical assets to the vendor in outsourcing but often gives away its people as well.

Added to all these this paper advocates adequate supporting infrastructures, commitment by top management, and development of objective performance criteria as factors that contribute to successful outsourcing. Performance metrics for an outsourcing engagement objective that are quantifiable and collectible at a reasonable cost should be properly defined, and should be metrics which can be benchmarked against performance of other organisations and providers. Other factors identified among the top priorities in successful outsourcing include adequate performance feedback, emphasis on both short and long-term benefits, and anticipation of change for both good and bad times and accommodation of cycles of demand that require an adjustment in services. The success of outsourcing is enhanced by an understanding and adaption to new styles of management required for the alliance; learning and understanding of the cultural differences between the organizations; commitment to succeed; strategic goal convergence; sufficient trust; and realistic expectations.

Laabs (2008) Mullin (2006) and Grant (2006) also identify good organisational communication, clear expectations, flexibility, keeping contracts long, and taking a strategic rather than a tactical approach to outsourcing activities.

There is also change management. The only constant factor that affects business organisation is change. Change arises from various methods and practices, involved in the performance of various human resource activities.

Managers have a number of fears concerned with outsourcing human resources such as loss of control, loss of personal touch and doubts about the quality and commitment of external staff all of which must be adequately addressed for outsourcing efforts to be successful.

\section{The Prospects of Outsourcing}

The global imperative for outsourcing is accelerating. To compete globally, organizations have to look at efficiency and cost containment rather than relying strictly on revenue increases. Organizations seek to enhance their competitive positions by cutting costs and maintaining quality through more reliance on outside service

providers for activities viewed as supplementary to their core businesses. The trend is for 
outsourcing relationships to function more as partnerships. Findings of studies like Elmuti, (2003); Lojeski (2004); Gottfredson, et al (2005) and Leavy (2007) show that the strategy of outsourcing indeed significantly improves organizational performance. In a rivalry intensity environment, many organizations use outsourcing as a way to perform routine business functions to enable them focus corporate resources mainly on those activities where clear differentiation advantage can be developed in their value chain to satisfy their customers.

However, there could be negative long-term consequences of outsourcing resulting from an organization's dependence on independent service providers. Such reliance on outsourcing may make it inherently difficult for the organization to sustain its long-term competitive advantages without engaging in the developmental activities of the constantly evolving technologies. Control over propriety often limits the human resource activities which organizations farm out to third parties. Fear of opportunistic behaviours also limits the perceived impact of outsourcing (especially of human resources) on organization performance.

For any human resource outsourcing strategy to work effectively, an organization must proactively manage its outsourcing strategies by establishing top management commitment as well as global sourcing structures and processes. Organizations that have not raised their sourcing approach to global, strategic level may already be behind in terms of quality, cost, delivery, technology, performance, and customer service. Factors such as pay level, promotional opportunities and demand uncertainty should be considered when deciding to outsource human resource functions or activities.

Training courses and seminar sessions can be employed to transfer the knowledge and skills of outsourcing providers to internal employees and to ensure that internal employees have knowledge regarding the outsourcing process. The development of training programmes to improve workforce skills, knowledge, and capability will benefit the organization in the long term. A strong training programme established by the organization and outsourcing provider will benefit employees through a higher sense of job security, job advancement, and career opportunities and consequently create a high degree of employee commitment.

To avoid the negative attitudes of employees regarding outsourcing function, the importance of employee perceptions and relationship management are significant. An organization should deal with the evaluation system using evaluation tools which will be used to check-off the category of the outsourcing process.

\section{Conclusion}

This paper concludes that the human resource outsourcing policy of any organization has implication on its job performance. Outsourcing is a strategic tool that can be used as a business survival strategy. It can be effective in fighting competition and maintaining competitive edge. However, its administration must be with caution. Improper administration could lead to serious problems for the organization. The degree of outsourcing in an organization should be dependent on the performance. High performer organizations need little or no outsourcing while a low performer may require outsourcing of needed employees to boost productivity. Outsourcing policies should be appraised, to ensure its suitability and ability to achieve desired goals. Extra attention should be paid to organizations to which human resource functions have been outsourced for their 
adequate judgments without self interest or bias.

\section{References}

Aswathappa (2006) The New Frontier of Experience Innovation. MIT SLOAN Management Review, Summer 2006

Bowersox, Donald J. (1994), "The Strategic Benefits of logistics Alliances", Harvard business' Review, 68 (July/August), 36 - 45

Carney (1997) "Outsourcing of Public Sector Services-The Moral Hazards, "Retrieved: April 21, 2013 from http://www.it-analysis.com

Drucker P.F. (2003). "Management Tasks, Responsibility Practices, Oxford, Butterworth Heinemann.

Dwyer, F \& Tanner, J (1999), Business Marketing: Connecting Strategy, Relationships, and Learning, Singapore: Mc-Graw-Hill International Editions,

Elmuti Dean (2003), The perceived Impact of outsourcing on organisational Performance. American Journal of Production Operations Fall 2003: Vol. 18 No 2

Foster (1999) "Myths about Jobs and Outsourcing", Retrieved: April 19, 2005 from http://www.heritage.org

Goffredson R, Puryear O, and Philips, G (2005) Outsourcing and Cost Saving Advantage, Public Sector Journal Vol.33 No.5.

Grant, R. (2006) Outsourcing and Subcontracting. USA, McGraw Hill.

Gregg, P. (2004), Business Outsourcing, London, Faber and Feber Publishing.

Hamel, G. (2004) 'Strategy Innovation and the Quest to Value," Sloan Management Review, 39 (2): 7-14

Jennings, F. (1996) Outsourcing and Business Organization, Lagos, Longman Publishers. Jones, Y. (1999) Competitiveness and Outsourcing, USA, McGraw Hill.

Laabs, T.U. (2008) Public Sector Outsourcing in the Federated Economy, Maryland, Atlantic Publisher

Leavy, Brian (2007), Outsourcing Strategies: opportunities and Risks. Strategy and leadership, Vol32. No. 6

Lojeski (2004) Challenges of public Sector Outsourcing in Human Resource professionals. w.w.w.wikipedia.com.

Mullin Bruce (2006), "functional Spin-off: A Key to Anticipating Change in Distribution Structure," Journal of marketing, Vo1 37 PP18-25

Murray, J. Y. (2001) Strategic Alliance - Based Global Sourcing Strategy for Competitive Advantage: A Conceptual Framework and Research Proposal Journal of International Marketing Vol 9 No 4 Pg $30-57$

Sampson, R.C. (2007) "R\&D Alliances and Firm Performance: The Impact of Technological Diversity and Alliance Organisation on Innovation', Academy of Management Journal vol. 50,No2 264-286

Sinderman (1995) Managing Change Transition, London: Harvard Business Press. Wikipedia (2009) Http://en. Wikipedia. Org/wiki/outsourcing 2009 